\title{
Hypoxia and reduced salinity exacerbate the effects of oil exposure on sheepshead minnow (Cyprinodon variegatus) reproduction
}

\author{
Lindsay Jasperse ${ }^{\mathrm{a}, *}$, Milton Levin ${ }^{\mathrm{a}}$, Kara Rogers ${ }^{\mathrm{a}}$, Christopher Perkins ${ }^{\mathrm{b}}$, Thijs Bosker ${ }^{\mathrm{c}}$, \\ Robert J. Griffitt ${ }^{\mathrm{d}}$, Marisol Sepúlveda ${ }^{\mathrm{e}}$, Sylvain De Guise $\mathrm{e}^{\mathrm{a}, \mathrm{f}}$

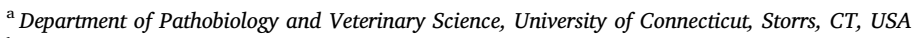 \\ ${ }^{\mathrm{b}}$ Center for Environmental Sciences and Engineering, University of Connecticut, Storrs, CT, USA \\ ${ }^{\mathrm{c}}$ Leiden University College/Institute of Environmental Sciences, Leiden University, The Hague, the Netherlands \\ ${ }^{\mathrm{d}}$ Department of Coastal Sciences, The University of Southern Mississippi, Ocean Springs, MS, USA \\ ${ }^{\mathrm{e}}$ Purdue University, Department of Forestry and Natural Resources, West Lafayette, IN, USA \\ ${ }^{\mathrm{f}}$ Connecticut Sea Grant College Program, Groton, CT, USA
}

\section{A R T I C L E I N F O}

\section{Keywords:}

Deepwater Horizon Oil Spill HEWAF

Polycyclic aromatic hydrocarbons (PAHs)

Aquatic toxicology

Combined stressors

Hypoxia

\begin{abstract}
A B S T R A C T
Estuaries of the northern Gulf of Mexico are dynamic environments, with fluctuations in salinity and dissolved oxygen, including areas of seasonal hypoxia. Fish that reside and reproduce in these estuaries, including sheepshead minnow (Cyprinodon variegatus; SHM), were at significant risk of oil exposure following the Deepwater Horizon oil spill. It is poorly understood how differences in environmental conditions during oil exposure impact its toxicity. The present study investigated the effects of crude oil high-energy water accommodated fraction (HEWAF) on SHM reproduction in three environmental scenarios (normoxic, hypoxic, and hypoxic with low salinity) to determine if differences in salinity (brackish vs low salinity) and dissolved oxygen (normoxia vs hypoxia) could exacerbate the effects of HEWAF-derived polycyclic aromatic hydrocarbons (PAHs). We observed that HEWAF exposure significantly increased liver somatic index of SHM compared to control, but this effect was not exacerbated by hypoxia or low salinity. HEWAF exposure also significantly decreased egg production and egg fertilization rate, but only in the hypoxic and hypoxic with low salinity scenarios. A significant correlation existed between body burdens of PAHs and reproductive endpoints, providing substantial evidence that oil exposure reduced reproductive capacity in SHM, across a range of environmental conditions. These data suggest that oil spill risk assessments that fail to consider other environmental stressors (i.e. hypoxia and salinity) may be underestimating risk.
\end{abstract}

\section{Introduction}

The explosion of the Deepwater Horizon (DWH) oil exploration platform on April $20^{\text {th }}, 2010$ began a catastrophic leak of crude oil into the northern Gulf of Mexico (GOM) that became the largest marine oil spill in US history (McNutt et al., 2012). Approximately 640 million liters of crude oil flowed into the GOM, creating an oil slick that covered more than $112,000 \mathrm{~km}^{2}$ of the ocean's surface (Beyer et al., 2016). Over the course of the three months the wellhead was leaking oil into the GOM, an estimated $1.7 \times 10^{11} \mathrm{~g}$ of $\mathrm{C}_{1}-\mathrm{C}_{5}$ hydrocarbons were released into the water column (Reddy et al., 2012). The spill also affected more than $2100 \mathrm{~km}$ of coastline, including wetlands and estuaries that provide habitat and nursery for many aquatic species (Beyer et al., 2016; Nixon et al., 2016). Coastlines of Texas, Louisiana,
Mississippi, Alabama, and Florida were all impacted by oil slicks that washed ashore (Nixon et al., 2016). In late April 2010, in an effort to limit the effects of oil on coastal habitats, the state of Louisiana initiated a massive diversion of freshwater from the Mississippi River into Barataria Bay and Breton Sound (Bianchi et al., 2011; Martínez et al., 2012). These freshwater diversions significantly reduced salinities in the estuaries of the northern GOM (Bianchi et al., 2011; Powers et al., 2017), but it is still undetermined if this effort was effective in reducing oiling to the Louisiana coast (Martínez et al., 2012).

Estuaries of the northern GOM are dynamic environments, with constant fluctuations in salinity and dissolved oxygen. Freshwater inflow from the Mississippi River causes a saline gradient in the estuaries that contributes to water stratification, usually during summer months (USEPA, 1999). The combination of water stratification, excess

\footnotetext{
* Corresponding author at: 61 North Eagleville Road, U-3089, Storrs, CT, 06269, USA.

E-mail address: lindsay.jasperse@uconn.edu (L. Jasperse).
} 
nutrients from the Mississippi River watershed, and a seasonal increase in temperature that increases biochemical oxygen demand contributes to seasonal hypoxia in the estuaries of the GOM, when dissolved oxygen levels drop below $2 \mathrm{mg} / \mathrm{L}$ (Diaz and Rosenberg, 2008; Thomas et al., 2007; USEPA, 2006). In 2010, the year the DWH oil spill occurred, the hypoxic zone of the GOM spanned $20,000 \mathrm{~km}^{2}$, along the coasts of Louisiana and eastern Texas (Turner et al., 2012).

Sheepshead minnows (Cyprinodon variegatus; SHM) are small-bodied ( $<8 \mathrm{~cm}$ long) euryhaline fish native to shallow waters along the east coast of the United States (Bigelow and Schroeder, 1953), including estuaries of the northern GOM. Sheepshead minnows have demonstrated a remarkable tolerance for wide ranges of salinities and dissolved oxygen levels (Nordlie, 2006). The isosmotic point for SHM has been reported to be 10.5 ppt (Adeyemi and Klerks, 2012). The SHM are also used extensively for toxicology studies as model organisms for estuarine environments, including aquatic toxicity testing of effluents by the United States Environmental Protection Agency (USEPA, 2002).

While fish can adapt to the environmental stress of variable estuarine conditions, it is not well understood how fish respond to the additional stress of oil exposure. Species that resided and reproduced in these estuaries, including SHM, were at significant risk of oil exposure, which may have been exacerbated by the fluctuating environmental conditions of the estuaries. Salinity is a particularly important environmental parameter to consider, as fish alter their method of osmoregulation in response to salinity changes, which will affect the route of exposure to oil components (Bosker et al., 2017). Fish hyperosmotic to the surrounding water perform osmoregulation primarily through the gills, while fish hypoosmotic to the surrounding water drink seawater to maintain osmotic balance (Bosker et al., 2017; Evans, 1997). Therefore, fish in higher salinities typically uptake contaminants through ingestion, while fish in lower salinity predominantly uptake contaminants through diffusion across the gills. The route of exposure can have a major impact on accumulation, as well as toxicity.

We have previously demonstrated that exposure to crude oil highenergy water accommodated fraction (HEWAF; an environmentally relevant PAH mixture), results in reduced egg production by SHM and developmental effects in two generations of offspring (Jasperse et al., 2019). Many other studies have also reported reproductive impairment in fish exposed to PAHs, including reduced egg production (BrownPeterson et al., 2013; Raimondo et al., 2016; Vignet et al., 2016), reduced serum estradiol levels (Pollino et al., 2009) delayed spawning and spermiation (Khan, 2012), and altered testicular development (Sundt and Bjorkblom, 2011). However, it remains unknown how adverse environmental conditions common to estuarine environments affect the sensitivity of SHM to the reproductive effects of HEWAF. The present study, therefore, investigated the effects of HEWAF on fish reproduction in three different environmental scenarios to determine if suboptimal environmental conditions exacerbate the effect of oil on somatic and reproductive endpoints.

\section{Methods}

\subsection{Sheepshead minnow}

Sheepshead minnows were obtained from the University of Southern Mississippi (USM), and bred to establish a colony at the University of Connecticut. All fish housing protocols and experimental procedures were approved under University of Connecticut's Institutional Animal Care and Use Committee protocol A15-059. Fish were housed in a $1500 \mathrm{~L}$ Mini Fish Farm (Pentair Aquatic Ecosystems, Apopka, FL). Water conditions for housing were: temperature $25^{\circ} \mathrm{C}$, salinity $15 \mathrm{ppt}$, and dissolved oxygen $6 \mathrm{mg} / \mathrm{L}$. Water quality tests were performed routinely, including daily testing for temperature, salinity, and dissolved oxygen, and weekly testing for ammonia, nitrite, nitrate, and $\mathrm{pH}$. Water changes were performed when water quality measurements were outside normal ranges (ammonia: $0-1 \mathrm{ppm}$, nitrites: 0 -
0.5 ppm, nitrates: 0-160 ppm). Adult fish were fed standard commercial flaked food (Aquatox Flake, Zeigler, Gardners, PA) during housing.

\subsection{Experimental conditions}

Three independent experiments were performed to assess the effect of HEWAF on SHM reproductive and somatic endpoints using three different environmental scenarios. The three experiments spanned a 1yr period and utilized fish from multiple cohorts. The three scenarios were normoxic (NORM), hypoxic (HYP), and hypoxic with low salinity (HYP-LS). Water temperature was maintained at $30{ }^{\circ} \mathrm{C}$ for all three scenarios. Dissolved oxygen levels were $6 \mathrm{mg} / \mathrm{L}$ for the normoxic exposure and $2.5 \mathrm{mg} / \mathrm{L}$ for both hypoxic exposures. Salinity was kept at 15 ppt for NORM and HYP scenarios and 10 ppt for the HYP-LS exposure. These salinities were chosen to match experiments previously performed testing the effects of HEWAF on SHM reproduction (Hedgpeth and Griffitt, 2016) and early life stage development (Griffitt, 2017; Simning, 2017). The SHM were hypoosmotic in the NORM and HYP scenarios, and slightly hyperosmotic in the HYP-LS scenario. Importantly, the water conditions of all scenarios were within normal ranges of the northern Gulf of Mexico (USEPA, 1999). During reproductive experiments, adult fish were fed flaked food twice a day and freshly hatched brine shrimp (Artemia salina) nauplii once a day.

\subsection{High-energy water accommodated fraction (HEWAF) preparation}

HEWAF was prepared according to protocols previously described (Incardona et al., 2013). Importantly, HEWAF has been demonstrated to be more similar than traditional WAF to the chemical composition of whole oil (Sandoval et al., 2017). Louisiana sweet crude (LSC) oil (surrogate, SO-20111116-MPDF-003) was supplied by British Petroleum. Oil was mixed with $3 \mathrm{~L}$ artificial seawater (15 ppt; Instant Ocean $^{\circledast}$, Blacksburg, VA, USA) in a Waring CB15 high-speed commercial blender (Torrington, CT, USA) at $1 \mathrm{~g}$ oil/L seawater for $1 \mathrm{~min}$ on low speed. The HEWAF was prepared in 7 batches (total of $21 \mathrm{~L}$ ), poured into a 23-L glass carboy, and allowed to settle for $1 \mathrm{~h}$. A peristaltic pump was used to collect HEWAF from the carboy, avoiding the oil-water interface. The HEWAF was mixed with artificial seawater in header tanks at dilutions (v/v) of $0 \%$ (no HEWAF; control), $1.25 \%$ (low HEWAF), and $12.5 \%$ (high HEWAF). Diluted HEWAF flowed into individual exposure tanks by passive flow. The flow-through exposure system required approximately $33 \mathrm{~L}$ of HEWAF daily. HEWAF for the HYP-LS scenario was prepared as described above, but with $10 \mathrm{ppt}$ artificial seawater.

\subsection{Chemical analyses}

For a subset of HEWAF preparations (NORM $n=5$; HYP $n=5$; HYP-LS $n=2$ ), a $500 \mathrm{~mL}$ sample of stock HEWAF was kept for chemical analysis by gas chromatography tandem mass spectroscopy (GC-MS/ MS) to determine the polycyclic aromatic hydrocarbon (PAH) composition using methods previously described (Rodgers et al., 2018). Briefly, HEWAF samples were passed across a methanol-conditioned Waters HLB SPE cartridge, eluted with acetonitrile, then analyzed using an Agilent 6890 gas chromatograph with Restek Rxi-5Sil MS column with splitless injection coupled to a Waters Quattro Micro tandem MS. An internal standard was used to quantify all peaks, and efficiency of extraction was assessed using surrogate standards. Standard quality assurance procedures were utilized, including analysis of duplicate samples, method blanks, matrix spike duplicates, and laboratory control samples. Reporting limits are shown in Table S1. Parent PAHs benzo(b)fluoranthene, benzo(k)fluoranthene, benzo(a)pyrene, dibenz (a,h)anthracene, indeno(1,2,3-cd)pyrene, and benzo(g,h,i)perylene were below limit of detection for all analyses.

Additionally, to evaluate the hydrocarbon exposure in the individual exposure tanks of the experimental system, a small sample of 
water was collected from each tank on each day of the $14 \mathrm{~d}$ exposure and preserved 1:1 in ethanol. Water samples were sonicated for $3 \mathrm{~min}$ to reduce PAH adhesion to the glass vial, and then analyzed on a fluorescence spectrophotometer using an excitation wavelength of $270 \mathrm{~nm}$ and emission range of $280-500 \mathrm{~nm}$ to detect total petroleum hydrocarbons (TPHs), including 2- to 4-ring aromatic hydrocarbons (Kim et al., 2010). The fluorescence of a control sample of artificial seawater from the control header tank (also preserved 1:1 with ethanol) was subtracted from tank samples to control for differences in salinity between experiments. The fluorescence detection method provided a fast and cost-effective alternative to GC/MS, and has been routinely used to monitor and characterize oil exposure (Kim et al., 2010). The fluorescence method of detection of TPHs is complimentary to, but not directly correlated with, concentrations of PAHs measured in stock HEWAF samples by GS-MS/MS. TPH concentrations were measured in water samples taken directly from exposure tanks, and therefore could have been influenced by uptake of hydrocarbons by fish.

\subsection{Reproductive test-acclimation and pre-exposure}

Adult SHM ( $>120 \mathrm{dph}$ ) were randomly assigned to $20 \mathrm{~L}$ glass aquaria, with three females and two males per tank (Cripe et al., 2009), as ascertained by sexually dimorphic SHM coloration (Page and Burr, 1991). Experimental tanks were set up on a flow-through system, similar to systems previously described (Jasperse et al., 2019; Manning et al., 1999). The flow-through system provided two turnovers of water per day, in order to maintain water quality and consistent oil exposure levels. Temperature was controlled by placing the tanks in a heated water bath, and temperature was monitored daily. Instant Ocean ${ }^{\circledR}$ was used to produce artificial seawater, and salinity was monitored using a Sybon Opticon Series FG100sa refractometer (Bethesda, MD, USA). For the NORM scenario, dissolved oxygen was maintained by bubbling oxygen into the individual exposure tanks. For the HYP and HYP-LS scenarios, a header tank of seawater was sparged with nitrogen $\left(\mathrm{N}_{2}\right)$ to reduce dissolved oxygen levels. Dissolved oxygen was monitored daily in a subset of the experimental tanks using YSI 5420 sensors (YSI Incorporated, Yellow Springs, $\mathrm{OH}$ ). Measured conditions for the NORM scenario were: temperature $29.8 \pm 0.2^{\circ} \mathrm{C}$ (mean $\pm \mathrm{SD}$ ), dissolved oxygen $5.6 \pm 0.9 \mathrm{mg} / \mathrm{L}$, and salinity $15 \pm 1 \mathrm{ppt}$. Measured conditions for the HYP scenario were: temperature $29.8 \pm 0.2{ }^{\circ} \mathrm{C}$, dissolved oxygen $2.6 \pm 0.6 \mathrm{mg} / \mathrm{L}$, and salinity $15 \pm 1 \mathrm{ppt}$. Measured conditions for the HYP-LS scenario were: temperature $29.8 \pm 0.2^{\circ} \mathrm{C}$, dissolved oxygen $2.9 \pm 0.5 \mathrm{mg} / \mathrm{L}$, and salinity $10 \pm 1 \mathrm{ppt}$.

Acclimation to the experimental conditions was achieved by gradually changing water parameters over a $10-\mathrm{d}$ period. Following acclimation, a 10-d pre-exposure period was performed to establish baseline egg production and determine exposure groups (Bosker et al., 2009). During the pre-exposure, a breeding net made of a PVC ring with fine nylon mesh $(335 \mu \mathrm{m})$ was placed into each tank to provide a spawning substrate for female fish. The breeding nets were removed daily to allow for enumeration of eggs spawned in each tank, then rinsed to remove eggs, and returned to the tank. During this pre-exposure period, eggs were not assessed for fertilization or hatching success. Tanks were distributed among treatment groups (6 tanks per treatment), following guidelines (Bosker et al., 2009) to ensure that any changes in egg production between treatments during the exposure phase were due to HEWAF exposure, not to natural variation in egg production between fish.

\subsection{Reproductive endpoints}

Eggs were collected daily from breeding nets throughout the 14-d exposure to determine cumulative egg production (CEP) during exposure. Egg production data were expressed per female to account for discrepancies in the 3 females to 2 males ratio, either from mortality of a fish during exposure, or misidentification of sex based on dimorphic coloration ( $3 \%$ misidentification rate). More specifically, during tank assignment, six male fish lacking the traditional blue coloration and caudal fin black stripe of mature male SHM were misidentified as females, and one female fish displaying partial male coloration was misidentified as male. Sex was confirmed during necropsy when reproductive organs could be dissected and visualized. Egg production values from each tank were then divided by the number of females in each tank.

On exposure days 7, 10, and 13, eggs were collected and kept in embryo cups (a cylinder of nylon mesh adhered to a petri dish) in tanks with clean, aerated artificial seawater (15 ppt) for determination of fertilization rate, a measure of male reproductive capacity. A maximum of 50 eggs were placed per embryo cup, with one embryo cup per tank. Fertilization rate was determined 2 days after egg collection by visualizing developing embryos using an inverted stereo microscope (Axiovert 200 M, Zeiss, CITY, Germany).

\subsection{Somatic endpoints}

Following the 14-d exposure, fish were netted and anaesthetized with $0.1 \mathrm{~g} / \mathrm{L}$ buffered tricaine methanesulfonate (MilliporeSigma, Burlington, MA), and standard length and wet weight determined. Fish were then euthanized by spinal severance (American Veterinary Medical Association, 2013) and dissected to remove liver and gonad, which were weighed to determine liver and gonad somatic indices (LSI: liver somatic index; GSI: gonad somatic index) for each individual fish. Somatic index was calculated as (organ wt/body wt) x 100 .

\subsection{PAH body burdens}

Fish carcasses (without livers and gonads) were analyzed for 16 parent PAHs and 8 alkyl PAHs. PAHs were extracted using the QuEChERs (Quick, Easy, Cheap, Effective, Rugged, and Safe) method (Johnson, 2012) in water, followed by the addition of acetonitrile, clean-up with magnesium sulfate and sodium acetate, and centrifugation. Extracts were then analyzed by ultra-performance liquid chromatography/tandem mass spectrometry photodiode array detection (UPLC/MS/MS/PDA), as previously described (Paruk et al., 2013; Seegar et al., 2015; Yeudakimau et al., 2013). Quality control data were within acceptable limits for all analyses. Reporting limits of parent PAHs are listed in Table S1. Parent PAHs benzo(b)fluoranthene, benzo (k)fluoranthene, benzo(a)pyrene, dibenz(a,h)anthracene, indeno(1,2,3cd)pyrene, and benzo(g,h,i)perylene were below limit of detection for all analyses and excluded from data tables.

Bioconcentration factors (BCFs) were calculated as previously described (Jonsson et al., 2004) using the equation $\mathrm{BCF}=\mathrm{C}_{\mathrm{F}} / \mathrm{C}_{\mathrm{W}}$, where $\mathrm{C}_{\mathrm{F}}$ is the $\mathrm{PAH}$ concentration measured in fish tissue (without liver and gonads), and $\mathrm{C}_{\mathrm{W}}$ is the concentration of PAHs in seawater.

\subsection{Statistical analyses}

The different environmental scenarios were three related but independent experiments and were therefore analyzed with separate statistical analyses. Survival curves were compared using log-rank tests. Two-way repeated measures analyses of variance (RM-ANOVAs) with Holm-Sidak test were used to determine differences in average egg production during pre-exposure and exposure periods of the reproductive test. One-way analyses of variance (ANOVAs) with HolmSidak test were used to determine differences between each HEWAF exposure and control for somatic endpoints, cumulative egg production, and fertilization rates. One-way ANOVAs with Holm-Sidak test were used to determine differences in BCFs among scenarios. Normality was assessed using Kolmogorov-Smirnov test, and equal variance was tested with the Levene median test. A one-way ANOVA on Ranks with Dunn's test was used when data violated normality assumptions. Correlation analyses of parent and alkyl PAH body burdens and experimental 
Table 1

Chemical composition of stock high-energy water accommodated fraction (HEWAF) among three environmental scenarios: normoxic (NORM), hypoxic (HYP), and hypoxic with low salinity (HYP-LS). All stock HEWAF samples were prepared with a loading rate of $1 \mathrm{~g}$ oil/L seawater. The HEWAFs were prepared with 15 ppt seawater for the NORM and HYP scenarios and $10 \mathrm{ppt}$ for the HYP-LS scenario. Samples were analyzed using gas chromatography - tandem mass spectrometry (GC-MS/MS) and are expressed as mean \pm standard error in ng/ml ( $\mathrm{n}=5$ for NORM and HYP, $\mathrm{n}=2$ for HYP-LS). Benzo(b)fluoranthene, benzo(k)fluoranthene, benzo(a)pyrene, dibenz(a,h)anthracene, indeno(1,2,3-cd)pyrene, and benzo(g,h,i)perylene were below limit of detection for all samples. Data for the normoxic scenario are reprinted from (Jasperse et al., 2019). $\mathrm{PAH}=$ polycyclic aromatic hydrocarbon; $\mathrm{ND}=$ not detected.

\begin{tabular}{|c|c|c|c|c|}
\hline \multicolumn{2}{|l|}{ Stock HEWAF } & \multirow{2}{*}{$\begin{array}{l}\text { NORM } \\
\mathrm{ng} / \mathrm{ml} \\
\mathrm{n}=5 \\
137 \pm 13\end{array}$} & \multirow{2}{*}{$\begin{array}{l}\text { HYP } \\
\mathrm{ng} / \mathrm{ml} \\
\mathrm{n}=5\end{array}$} & \multirow{2}{*}{$\begin{array}{l}\begin{array}{l}\text { HYP-LS } \\
\mathrm{ng} / \mathrm{ml} \\
\mathrm{n}=2\end{array} \\
84 \pm 5\end{array}$} \\
\hline Parent PAH & Total Parent PAHs & & & \\
\hline & Naphthalene & $119 \pm 13$ & $108 \pm 4$ & $79 \pm 4$ \\
\hline & Acenaphthylene & ND & ND & ND \\
\hline & Fluorene & $7 \pm 1$ & $5 \pm 1$ & $3 \pm 0.4$ \\
\hline & Acenaphthene & $1 \pm 0.1$ & ND & $2 \pm 0.1$ \\
\hline & Phenanthrene & $8 \pm 1$ & $6 \pm 1$ & ND \\
\hline & Anthracene & $3 \pm 0.2$ & ND & ND \\
\hline & Fluoranthene & ND & ND & ND \\
\hline & Pyrene & ND & $0.2 \pm 0.01$ & ND \\
\hline & Chrysene & $0.2 \pm 0.1$ & $0.2 \pm 0.02$ & ND \\
\hline & Benzo(a)anthracene & $0.4 \pm 0.02$ & $\mathrm{ND}$ & ND \\
\hline \multirow[t]{10}{*}{ Alkyl PAH } & Total Alkyl PAHs & $125 \pm 5$ & $122 \pm 4$ & $102 \pm 5$ \\
\hline & 2-methylnaphthalene & $42 \pm 2$ & $40 \pm 1$ & $43 \pm 1$ \\
\hline & 2,6-dimethylnaphthalene & $14 \pm 1$ & $12 \pm 1$ & $12 \pm 1$ \\
\hline & 1,3-dimethylnaphthalene & $34 \pm 1$ & $28 \pm 1$ & $26 \pm 1$ \\
\hline & 1,5-dimethylnaphthalene & $13 \pm 1$ & $11 \pm 1$ & $14 \pm 1$ \\
\hline & 2,3,5-trimethylnaphthalene & $2 \pm 0.2$ & $6 \pm 0.3$ & $1 \pm 0.2$ \\
\hline & 1-methylfluorene & $4 \pm 0.4$ & $7 \pm 0.4$ & $2 \pm 0.2$ \\
\hline & 3-methylphenanthrene & $5 \pm 1$ & $8 \pm 1$ & $1 \pm 0.02$ \\
\hline & 9-methylphenanthrene & $11 \pm 1$ & $10 \pm 1$ & $3 \pm 0.03$ \\
\hline & Alkyl:Parent PAH Ratio & 0.9 & 1.0 & 1.2 \\
\hline
\end{tabular}

endpoints with statistically significant differences between exposures were performed using Pearson Product Moment Correlation. Body burden data were pooled separately for males and females, into the number of tissue pools indicated in Table 2. Control fish were not included in the correlation analyses, as they had no variability in PAH body burdens (all below reporting limit). All analyses were performed using SigmaStat 3.5 software (Systat Software, San Jose, CA), using an alpha level of 0.05 for statistical significance. All data were presented as mean \pm standard error of the mean (SEM), unless indicated otherwise.

\section{Results}

\subsection{Chemical analyses}

Average total parent PAHs (tPAHs) for stock HEWAF was $137 \pm 13 \mathrm{ng} / \mathrm{mL}$ for the NORM scenario, $119 \pm 4 \mathrm{ng} / \mathrm{mL}$ for the HYP scenario, and $84 \pm 5 \mathrm{mg} / \mathrm{mL}$ for the HYP-LS scenario (Table 1). All HEWAF samples were predominantly comprised of naphthalene and alkylated naphthalene compounds. The HEWAFs had similar levels of parent PAHs and alkyl PAHs, with alkyl:parent PAH ratios of approximately 1 . Based on the measured mean tPAH concentration, the $1.25 \%$ HEWAF dilution ("low HEWAF") was determined to be 1.7, 1.5, and $1.1 \mathrm{ng} / \mathrm{mL}$ tPAHs for NORM, HYP, and HYP-LS scenarios, respectively. The 12.5\% HEWAF dilution ("high HEWAF") was determined to be 17 , 15 , and $10.5 \mathrm{ng} / \mathrm{mL}$ tPAHs for NORM, HYP, and HYP-LS scenarios, respectively.

Daily quantification of TPH in individual tanks of SHM measured using fluorescence indicated that exposure remained relatively steady throughout the $14 \mathrm{~d}$ exposure, and consistent between tanks of the same dilution (Figure S1). Moreover, fluorescence appeared to be similar across scenarios for tanks of the same exposure. As expected, fluorescence values indicated that high HEWAF exposure was 8-11 times higher in TPH concentration compared to the low HEWAF exposure.

Body burdens of parent and alkyl PAHs in SHM following exposure to low or high HEWAF are summarized in Table 2. For each scenario, fish from control tanks were pooled and all PAHs analyzed were below the limit of detection. Similar to stock HEWAF samples, body burdens of tPAHs in fish from low HEWAF exposure were highest in fish exposed in the NORM scenario, followed closely by HYP, and much lower in fish from HYP-LS (Table 2). Body burdens of tPAHs in female fish following high HEWAF exposure were higher in the HYP and HYP-LS scenarios than in the NORM scenario. Body burdens of tPAHs in male fish following high HEWAF exposure were highest in the HYP scenario and about $30-40 \%$ lower in the NORM and HYP-LS scenarios. In contrast to the equal ratio of alkyl:parent PAHs in the HEWAF, body burden data indicates an increased proportion of alkylated PAHs in fish tissue.

To facilitate the interpretation of differing body burdens given differing water concentrations among environmental scenarios, bioconcentration factors of PAHs (based on whole fish without livers and gonads) are reported in Table 3. The alkyl:parent PAH ratio of BCFs indicated that, across all scenarios, fish preferentially bioconcentrated alkyl PAHs. Moreover, fish exposed to low HEWAF in the HYP scenario had alkyl:parent PAH ratios approximately twice as high as fish exposed in the NORM scenario, suggesting that hypoxia tended to increase the bioconcentration of alkyl PAHs. Fish exposed to HEWAF in the HYP scenario had significantly higher BCFs for several parent and alkyl PAHs, compared to fish exposed in the NORM scenario (Table 3). In the HYP scenario, acenaphthene and anthracene were below detection limit in HEWAF, but detected in high levels in fish tissues, indicating substantial bioconcentration of these compounds in hypoxic conditions. In the HYP-LS scenario, phenanthrene and anthracene were below detection limit in HEWAF, but detected in high levels in fish tissues, demonstrating substantial bioconcentration of these compounds in conditions of combined hypoxia and low salinity. Interestingly, hypoxia tended to reduce bioconcentration of high molecular weight alkyl PAHs (Table 3), suggesting that the effect of hypoxia on bioconcentration depends on the specific size or structural properties of the PAH.

Female fish exposed to low HEWAF in the HYP-LS scenario had significantly lower bioconcentration of tPAHs compared to females exposed in the NORM and HYP scenario ( $\mathrm{p}<0.001)$. Low salinity also 


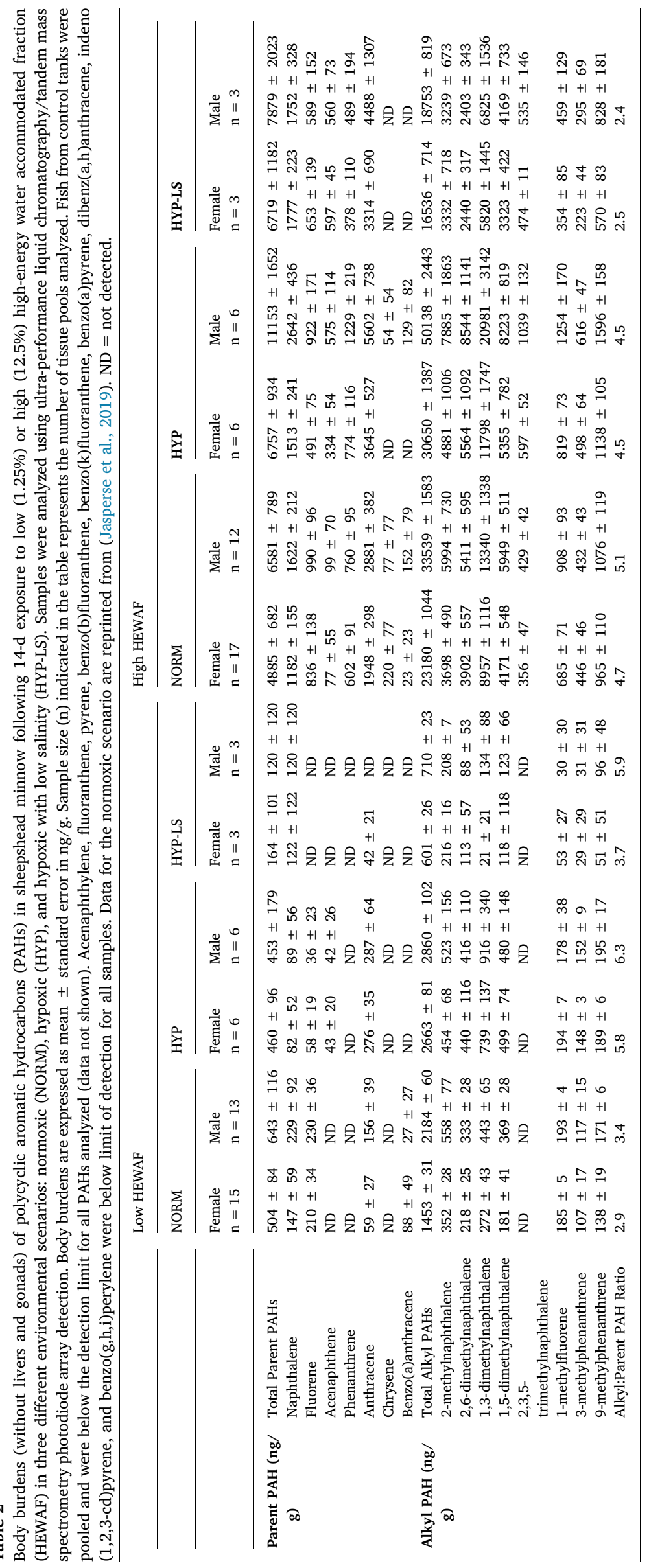


Table 3

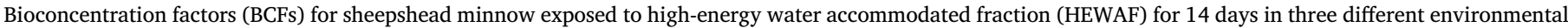

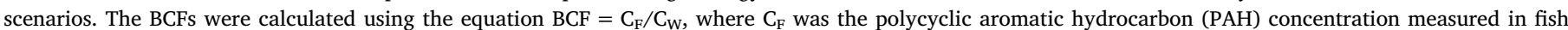

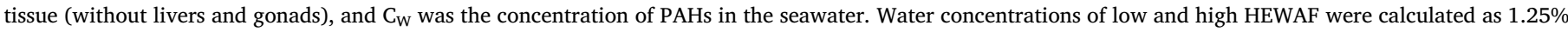

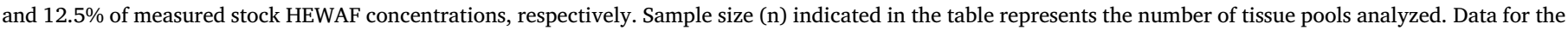

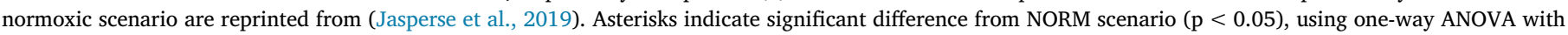

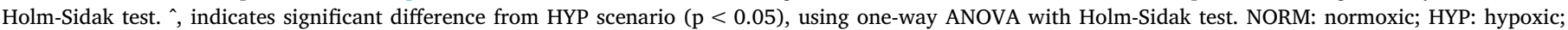

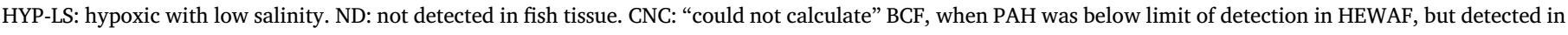
fish tissue.

\begin{tabular}{ll}
\hline Parent PAH & Total PAHs \\
& Naphthalene \\
& Acenaphthylene \\
& Fluorene \\
& Acenaphthene \\
& Phenanthrene \\
& Anthracene \\
& Fluoranthene \\
& Pyrene \\
& Chrysene \\
& Benzo(a)anthracene \\
& Total Alkyl PAHs \\
& 2-methylnaphthalene \\
2,6-dimethylnaphthalene & 1,3-dimethylnaphthalene \\
1,5-dimethylnaphthalene & 2,3,5-trimethylnaphthalene \\
& 1-methylfluorene \\
3-methylphenanthrene & 9-methylphenanthrene \\
Alkyl:Parent PAH Ratio
\end{tabular}

\begin{tabular}{|c|c|c|c|c|c|c|c|c|c|c|c|}
\hline \multicolumn{6}{|c|}{ Low HEWAF } & \multicolumn{6}{|c|}{ High HEWAF } \\
\hline \multicolumn{2}{|l|}{ NORM } & \multicolumn{2}{|l|}{ HYP } & \multicolumn{2}{|l|}{ HYP-LS } & \multicolumn{2}{|l|}{ NORM } & \multicolumn{2}{|l|}{ HYP } & \multicolumn{2}{|l|}{ HYP-LS } \\
\hline $\begin{array}{l}\text { Female } \\
n=15\end{array}$ & $\begin{array}{l}\text { Male } \\
\mathrm{n}=13\end{array}$ & $\begin{array}{l}\text { Female } \\
\mathrm{n}=6\end{array}$ & $\begin{array}{l}\text { Male } \\
\mathrm{n}=6\end{array}$ & $\begin{array}{l}\text { Female } \\
\mathrm{n}=3\end{array}$ & $\begin{array}{l}\text { Male } \\
\mathrm{n}=3\end{array}$ & $\begin{array}{l}\text { Female } \\
\mathrm{n}=17\end{array}$ & $\begin{array}{l}\text { Male } \\
\mathrm{n}=12\end{array}$ & $\begin{array}{l}\text { Female } \\
\mathrm{n}=6\end{array}$ & $\begin{array}{l}\text { Male } \\
\mathrm{n}=6\end{array}$ & $\begin{array}{l}\text { Female } \\
\mathrm{n}=3\end{array}$ & $\begin{array}{l}\text { Male } \\
\mathrm{n}=3\end{array}$ \\
\hline 295 & 376 & 309 & 305 & $155^{*^{\wedge}}$ & 114 & 286 & 385 & 455 & $750 *$ & 637 & 747 \\
\hline 99 & 155 & 61 & 66 & 124 & 122 & 80 & 109 & 112 & $195^{*}$ & $180^{*}$ & 178 \\
\hline ND & ND & ND & ND & ND & ND & ND & ND & ND & ND & ND & ND \\
\hline 2368 & 2603 & 950 & $590 *$ & $0^{*}$ & $0 *$ & 944 & 1118 & 804 & 1510 & 1494 & 1348 \\
\hline 0 & 0 & $\mathrm{CNC}$ & $\mathrm{CNC}$ & 0 & 0 & 457 & 588 & $\mathrm{CNC}$ & CNC & 2232 & 2093 \\
\hline 0 & 0 & 0 & 0 & ND & ND & 625 & 789 & 1093 & 1736 & $\mathrm{CNC}$ & $\mathrm{CNC}$ \\
\hline 1827 & 4823 & $\mathrm{CNC}$ & $\mathrm{CNC}$ & $\mathrm{CNC}$ & ND & 6016 & 8898 & CNC & $\mathrm{CNC}$ & $\mathrm{CNC}$ & $\mathrm{CNC}$ \\
\hline ND & ND & ND & ND & ND & ND & ND & ND & ND & ND & ND & ND \\
\hline ND & ND & 0 & 0 & ND & ND & ND & ND & 0 & 0 & ND & ND \\
\hline 0 & 0 & 0 & 0 & ND & ND & 8819 & 3094 & 0 & 2618 & ND & ND \\
\hline 18374 & 5632 & ND & ND & ND & ND & 472 & 3170 & ND & 20640 & ND & ND \\
\hline 924 & 1394 & $1746 *$ & 1873 & $471^{\wedge}$ & 555 & 1479 & 2141 & 2008 & $3284^{*}$ & 1294 & $1468^{\wedge}$ \\
\hline 667 & 1060 & 913 & 1052 & $398^{\wedge}$ & $383^{*}$ & 702 & 1138 & 981 & 1585 & 614 & 597 \\
\hline 1220 & 1859 & $2906^{*}$ & 2748 & $784^{\wedge}$ & $611^{\wedge}$ & 2180 & 3024 & 3675 & $5643^{*}$ & 1694 & $1668^{\wedge}$ \\
\hline 633 & 1031 & $2086^{*}$ & 2585 & $65^{\wedge}$ & $415^{\wedge}$ & 2085 & 3105 & 3330 & $5921^{*}$ & 1801 & $2112^{\wedge}$ \\
\hline 1127 & 2294 & $3515^{*}$ & 3381 & $661^{\wedge}$ & $689^{\wedge}$ & 2594 & 3701 & 3772 & $5793^{*}$ & 1861 & $2335^{\wedge}$ \\
\hline 0 & 0 & 0 & 0 & 0 & 0 & 1551 & 1872 & 858 & 1494 & $2532^{\wedge}$ & $2858^{\wedge}$ \\
\hline 3356 & 3507 & $2161^{*}$ & $1983^{*}$ & 2204 & 1248 & 1246 & 1652 & 912 & 1397 & 1472 & 1909 \\
\hline 1880 & 2071 & 1552 & 1594 & 2289 & 2446 & 787 & 762 & 522 & 646 & $1760^{\wedge}$ & $2328^{* \wedge}$ \\
\hline 1015 & 1257 & 1489 & 1537 & 1517 & 2856 & 709 & 791 & 897 & 1258 & $1696^{*}$ & $2464 *$ \\
\hline 3.2 & 3.7 & 5.7 & 6.1 & 3.0 & 4.9 & 5.2 & 5.6 & 4.4 & 4.4 & 2.0 & 2.0 \\
\hline
\end{tabular}

Table 4

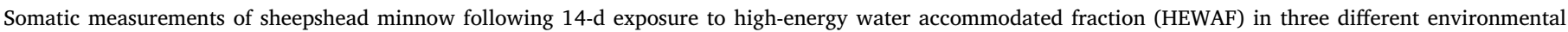

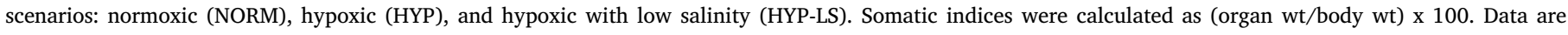

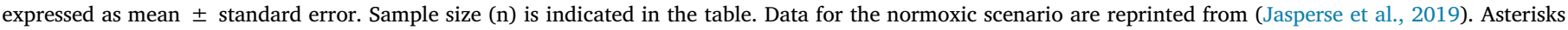
indicate significant difference from control ( $\mathrm{p}<0.05)$, using one-way ANOVA with Holm-Sidak test.

\begin{tabular}{|c|c|c|c|c|c|c|c|}
\hline Scenario & Sex & HEWAF & $\mathrm{n}$ & Length (mm) & $\begin{array}{l}\text { Weight } \\
\text { (g) }\end{array}$ & LSI & GSI \\
\hline \multirow[t]{6}{*}{ NORM } & \multirow[t]{3}{*}{ Female } & Control & 17 & $36 \pm 1$ & $2.58 \pm 0.40$ & $2.07 \pm 0.26$ & $3.31 \pm 0.45$ \\
\hline & & Low & 15 & $37 \pm 1$ & $2.36 \pm 0.41$ & $2.88 \pm 0.35$ & $4.14 \pm 0.46$ \\
\hline & & High & 17 & $38 \pm 1$ & $1.91 \pm 0.20$ & $3.72 \pm 0.39^{*}$ & $4.34 \pm 0.79$ \\
\hline & \multirow[t]{3}{*}{ Male } & Control & 13 & $43 \pm 1$ & $3.51 \pm 0.58$ & $1.99 \pm 0.35$ & $0.44 \pm 0.15$ \\
\hline & & Low & 13 & $44 \pm 2$ & $4.58 \pm 0.62$ & $1.83 \pm 0.16$ & $0.39 \pm 0.06$ \\
\hline & & High & 12 & $42 \pm 2$ & $2.63 \pm 0.40$ & $3.16 \pm 0.31 *$ & $0.44 \pm 0.07$ \\
\hline \multirow[t]{6}{*}{ HYP } & \multirow[t]{3}{*}{ Female } & Control & 18 & $37 \pm 1$ & $2.02 \pm 0.16$ & $1.96 \pm 0.16$ & $2.32 \pm 0.21$ \\
\hline & & Low & 18 & $37 \pm 1$ & $1.77 \pm 0.14$ & $2.32 \pm 0.20$ & $3.20 \pm 0.29$ \\
\hline & & High & 17 & $38 \pm 1$ & $1.87 \pm 0.15$ & $3.11 \pm 0.34^{*}$ & $2.97 \pm 0.33$ \\
\hline & \multirow[t]{3}{*}{ Male } & Control & 11 & $45 \pm 1$ & $3.75 \pm 0.30$ & $1.12 \pm 0.18$ & $0.37 \pm 0.04$ \\
\hline & & Low & 11 & $45 \pm 2$ & $3.75 \pm 0.40$ & $1.76 \pm 0.19^{*}$ & $0.42 \pm 0.05$ \\
\hline & & High & 12 & $44 \pm 2$ & $3.33 \pm 0.36$ & $2.13 \pm 0.11^{*}$ & $0.42 \pm 0.05$ \\
\hline \multirow[t]{6}{*}{ HYP-LS } & \multirow[t]{3}{*}{ Female } & Control & 17 & $30 \pm 1$ & $0.99 \pm 0.06$ & $3.11 \pm 0.29$ & $4.46 \pm 0.47$ \\
\hline & & Low & 18 & $32 \pm 1$ & $1.22 \pm 0.13$ & $3.26 \pm 0.21$ & $3.87 \pm 0.37$ \\
\hline & & High & 18 & $31 \pm 1$ & $0.94 \pm 0.07$ & $3.53 \pm 0.48$ & $4.02 \pm 0.50$ \\
\hline & \multirow[t]{3}{*}{ Male } & Control & 13 & $42 \pm 1$ & $2.63 \pm 0.24$ & $1.30 \pm 0.19$ & $0.64 \pm 0.11$ \\
\hline & & Low & 12 & $43 \pm 1$ & $2.85 \pm 0.24$ & $1.62 \pm 0.23$ & $0.69 \pm 0.08$ \\
\hline & & High & 8 & $40 \pm 2$ & $2.10 \pm 0.26$ & $2.36 \pm 0.27^{*}$ & $0.72 \pm 0.09$ \\
\hline
\end{tabular}

appeared to affect the bioconcentration of alkyl PAHs, though the pattern was not consistent across compounds. Fish exposed to low or high HEWAF in the HYP-LS scenario had significantly lower BCFs of total alkyl PAHs (low HEWAF: $p<0.001$; high HEWAF: $p=0.013$ ), as well as several low molecular weight alkyl PAHs, compared to fish exposed in the HYP scenario. Alternatively, fish exposed to high HEWAF in the HYP-LS scenario had significantly higher BCFs of high molecular weight alkyl PAHs, compared to fish exposed in other environmental scenarios.

\subsection{Survival}

Exposure to HEWAF resulted in minimal mortality, with an average survival rate of $96 \%$ across all exposures (Figure S2). There were no 


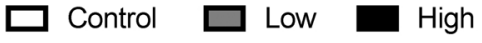

A

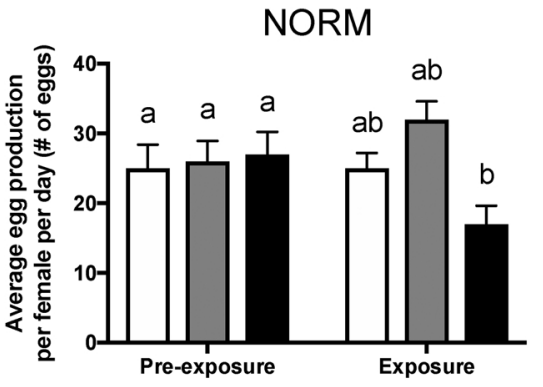

B

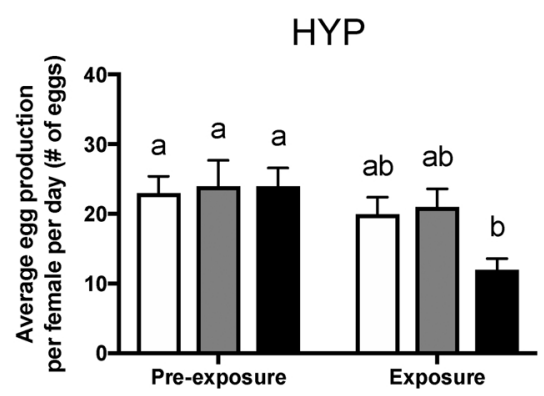

C

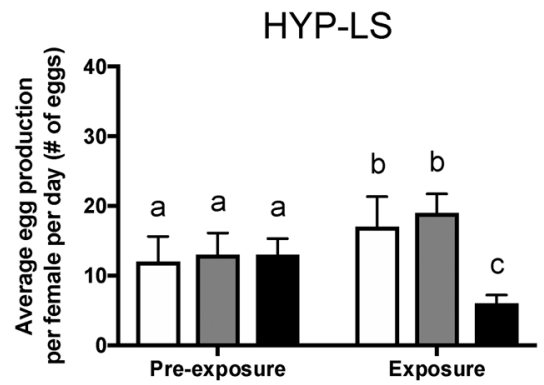

D

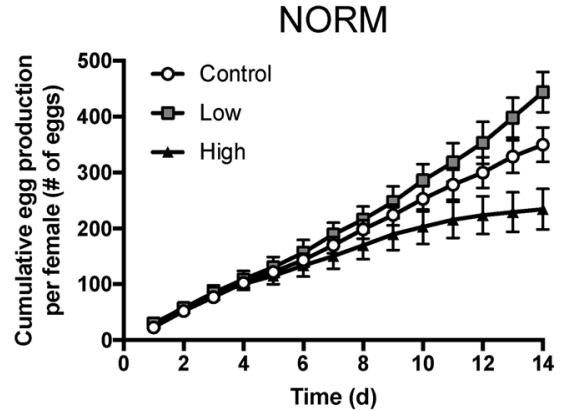

$\mathbf{E}$

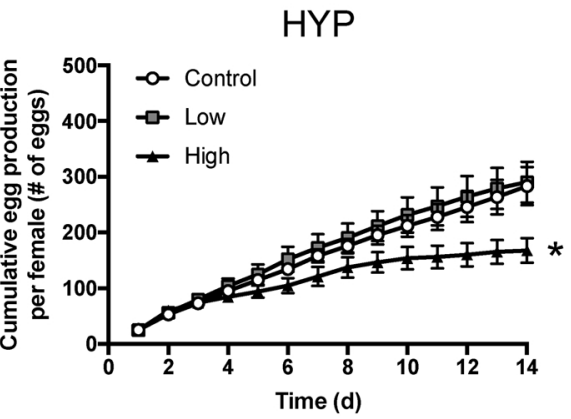

$\mathbf{F}$

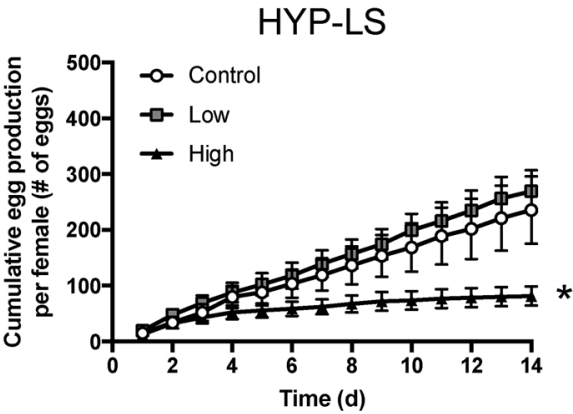

Fig. 1. Effect of high-energy water accommodated fraction (HEWAF) exposure on egg production of sheepshead minnow in three different environmental scenarios: normoxic (NORM), hypoxic (HYP), and hypoxic with low salinity (HYP-LS). A-C) Average egg production per female per day during the pre-exposure (10 d) and exposure (14 d) periods in NORM (A), HYP (B), and HYP-LS (C) scenarios. Different letters indicate significant differences using two-way RM ANOVA with Holm-Sidak test ( $\mathrm{p}<0.05$ ). D-F) Cumulative egg production per female during exposure to HEWAF in NORM (D), HYP (E), and HYP-LS (F) scenarios. Asterisks indicate significant differences from control at the end of the HEWAF exposure period, using one-way ANOVA with HolmSidak test $(\mathrm{p}<0.05)$. All data are expressed as mean \pm standard error. $\mathrm{n}=6$ tanks per treatment, with 3 females and 2 males per tank. Data for the normoxic scenario are reprinted from (Jasperse et al., 2019). significant differences in survival of SHM throughout the reproductive test in the NORM $(p=0.366)$ or HYP $(p=1.00)$ scenarios. In the HYPLS scenario, high HEWAF exposure resulted in a survival rate of $87 \%$ over the 14-d exposure, which was significantly lower than controls $(\mathrm{p}=0.04)$.

\subsection{Somatic endpoints}

Morphometrics following HEWAF exposure in different scenarios are described in Table 4. There were no significant effects of HEWAF exposure on length, weight, or GSI. In the NORM and HYP scenarios, both male and female SHM exposed to high HEWAF had significantly increased LSI compared to controls. Additionally, in the HYP scenario, low HEWAF exposure also resulted in increased LSI in male fish. In the HYP-LS scenario, there were no significant changes in female morphometrics, but males exposed to high HEWAF had significantly increased LSI.

\subsection{Reproductive endpoints - egg production}

There were no significant differences in average egg production during the pre-exposure period in all scenarios. In all three scenarios, high HEWAF resulted in significantly lower average egg production during the exposure period compared to the same tanks during the pre- exposure period (Fig. 1A-C). Within the HYP-LS scenario, but not the NORM or HYP scenarios, high HEWAF also resulted in significantly lower average egg production during the exposure period compared to control tanks (Fig. 1A-C). Both control and low HEWAF fish in the HYPLS scenario produced significantly more eggs in the exposure period compared to the pre-exposure period. This may suggest that fish took longer than the 10-d pre-exposure period to fully adjust to low salinity and optimize egg production.

The effect of HEWAF on cumulative egg production (CEP) over the 14-d exposure is shown to demonstrate kinetics of reproductive effects over time in the different environmental scenarios (Fig. 1D-F). In the NORM scenario, there were no significant differences in CEP between low or high HEWAF exposure and controls (Fig. 1D). However, exposure to high HEWAF significantly reduced CEP in the HYP scenario (41\% reduction Fig. 1E) and HYP-LS scenario (65\% reduction; Fig. 1F).

\subsection{Reproductive endpoints - fertilization rate}

Fertilization was analyzed in eggs collected from breeding nets on days 7, 10, and 13 of HEWAF parental exposure. For the NORM scenario, data from eggs collected on day 13 were excluded from analyses because of a water heater malfunction. In the NORM scenario, HEWAF exposure did not significantly affect fertilization rate of eggs collected on day 7 or 10 of parental exposure (Fig. 2A). In the HYP scenario, high 

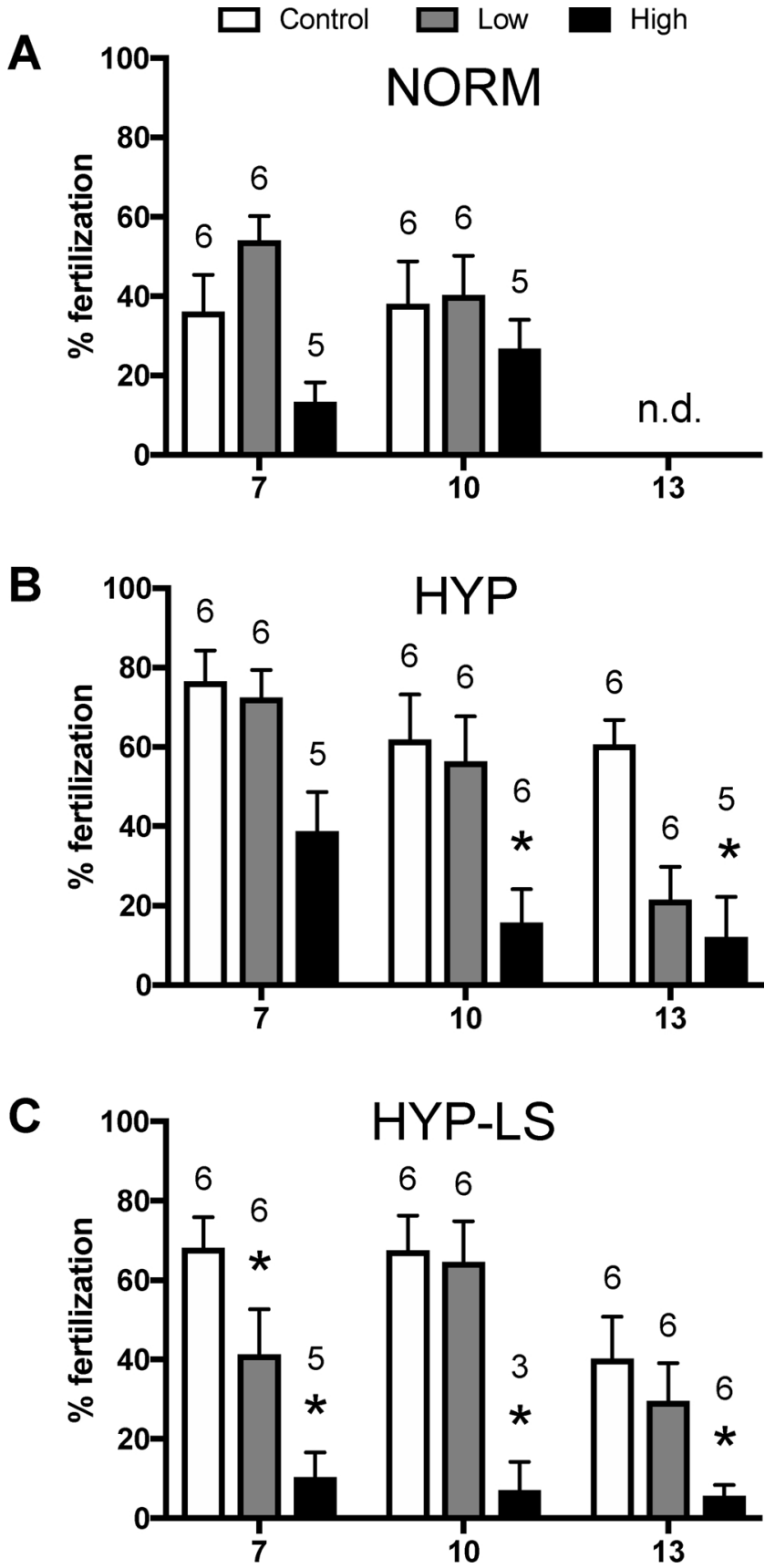

Fig. 2. Effect of high-energy water accommodated fraction (HEWAF) on fertilization rate of embryos produced by sheepshead minnow exposed in three different environmental scenarios: (A) normoxic (NORM), (B) hypoxic (HYP), and (C) hypoxic with low salinity (HYP-LS). Fertilization rate was assessed in eggs collected following 7, 10, and 13 days of parental HEWAF exposure. Asterisks indicate a significant difference from control within scenarios and egg collections. All data are expressed as mean \pm standard error and were analyzed using one-way ANOVA with Holm-Sidak test $(\mathrm{p}<0.05)$. Sample sizes (number of tanks) are indicated by the data labels in the figure. Data for the normoxic scenario are reprinted from (Jasperse et al., 2019). n.d. = no data.

HEWAF exposure significantly reduced fertilization rate compared to controls in eggs collected on day 10 and 13 of parental exposure, but not in eggs collected on day 7 (Fig. 2B). In the HYP-LS scenario, high HEWAF exposure reduced fertilization rate compared to controls in eggs collected on days 7, 10, and 13 of parental exposure (Fig. 2C). Furthermore, low HEWAF also significantly reduced fertilization rate of eggs collected on day 7 of parental exposure in the HYP-LS scenario.

\subsection{Correlation analyses}

Fertilization rate of eggs collected on day 10 of parental exposure was negatively correlated with body burdens of PAHs in male fish in both the HYP and HYP-LS scenarios (Table 5). In the HYP scenario, fertilization rate was negatively correlated with body burdens of tPAHs, five parent PAHs, total alkyl PAHs, and all eight alkyl PAHs. In the HYPLS scenario, fertilization rate was negatively correlated with body burdens of naphthalene and acenaphthene, total alkyl PAHs, and three alkyl PAHs. Within the NORM scenario, LSI was positively correlated with body burdens of tPAHs, five of the seven parent PAHs detected in tissues, total alkyl PAHs, and six of the eight alkyl PAHs (Table 5). Within the HYP-LS scenario, CEP was negatively correlated with body burdens of tPAHs, three parent PAHs, and three alkyl PAHs in female fish. Graphic representations of correlations of significantly altered endpoints with tissue tPAHs are shown in Figure S3.

\section{Discussion}

The present study demonstrated that HEWAF exposure modulated morphometric parameters (LSI) as well as reproductive fitness (egg production and fertilization rate) in SHM. Correlation analyses supported a relationship between body burdens of PAHs and these endpoints, suggesting that oil exposure may contribute to altered liver size and reduced reproductive capacity in SHM in the present study. Moreover, suboptimal environmental scenarios appeared to exacerbate the toxicity of HEWAF (increased mortality in HYP-LS scenario), and the severity of reproductive effects, supporting prior research that environmental conditions affect how fish respond to oil exposure (Hedgpeth and Griffitt, 2016; Rodgers et al., 2018).

While it is unknown precisely what level of oil exposure SHM experienced in the GOM, a publicly available database of tissue chemistry results from 32 Natural Resource Damage Assessment studies indicates that whole body tissue samples of numerous fish species ( $>400$ samples from $>40$ species) collected in the GOM between August 2010 and October 2011 had naphthalene concentrations ranging between 0 and approximately $100 \mathrm{ppb}$ (BP Gulf Science Data, 2015). The tissue concentrations of naphthalene in fish exposed to low HEWAF in the present study fall near the upper range of concentrations measured in fish in the GOM following DWH, while fish exposed to high HEWAF were about 10-20 times higher. It is possible that hydrocarbon concentrations in fish collected from the GOM would have been higher if samples were measured in times and areas of peak oiling. For example, it has been estimated, based on transcriptomic signatures, that during peak oiling of Barataria Bay, LA, resident species were exposed to between 300 and 3000 ppb tPAHs (Pilcher et al., 2014). Importantly, the tPAH exposure concentrations used in the present study (1.1-17 ppb) are within the range of concentrations measured in the GOM following $\mathrm{DWH}$, as reported in the largest publicly available database of GOM water chemistry data (BP Gulf Science Data, 2016). In sum, the HEWAF exposures of the present study appear to represent an environmentally realistic exposure for SHM in the GOM following the DWH oil spill.

Body burdens of PAHs and BCFs were assessed at the end of the 14-d exposure, and therefore represent the net result of dynamic processes such as absorption, metabolic biotransformation, and excretion of the hydrocarbons that were occurring throughout the exposure period (Arnot and Gobas, 2006; Heath, 1995). The removal of livers and gonads from SHM prior to chemical analyses limited the interpretation of body burdens and BCFs between males and female fish. However, livers and gonads were removed from all fish in all scenarios, which allowed for comparisons of body burdens and BCFs among scenarios. There is strong evidence that SHM absorbed PAHs from the water in all environmental scenarios, given the detection of parent and alkyl PAHs in exposed fish but not in control fish. Moreover, fish exposed to high HEWAF had increased LSI in all scenarios except for females exposed in the HYP-LS scenario, suggesting that the combination of hypoxia and 
Table 5

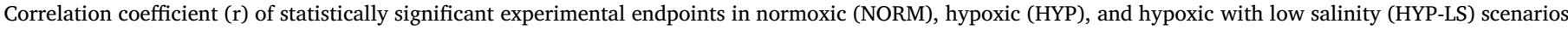

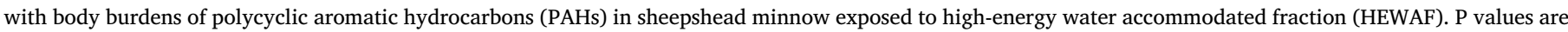

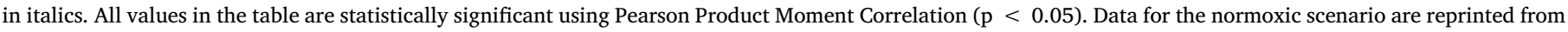

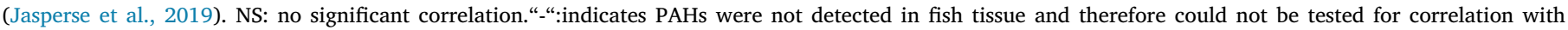
endpoints .

\begin{tabular}{|c|c|c|c|c|c|}
\hline & & \multirow{2}{*}{$\begin{array}{l}\text { NORM } \\
\text { Liver Somatic Index }\end{array}$} & \multirow{2}{*}{$\begin{array}{l}\text { HYP } \\
\text { Fertilization Rate Day } 10\end{array}$} & \multicolumn{2}{|l|}{ HYP-LS } \\
\hline & & & & Cumulative Egg Production & Fertilization Rate Day 10 \\
\hline \multirow[t]{11}{*}{ Parent PAH } & Total Parent PAHs & 0.4930 .014 & -0.6570 .020 & -0.8140 .049 & NS \\
\hline & Naphthalene & 0.4830 .017 & -0.6720 .017 & -0.8480 .033 & -0.8470 .033 \\
\hline & Acenaphthylene & - & - & - & - \\
\hline & Fluorene & 0.6520 .001 & -0.6670 .018 & -0.8140 .049 & NS \\
\hline & Acenaphthene & NS & -0.6460 .023 & -0.9100 .012 & -0.8780 .021 \\
\hline & Phenanthrene & 0.4930 .014 & -0.6880 .013 & NS & NS \\
\hline & Anthracene & 0.4260 .038 & -0.6260 .030 & NS & NS \\
\hline & Fluoranthene & - & - & - & - \\
\hline & Pyrene & - & - & - & - \\
\hline & Chrysene & 0.4820 .017 & NS & - & - \\
\hline & Benzo(a)anthracene & NS & NS & - & - \\
\hline \multirow[t]{10}{*}{ Alkyl PAH } & Total Alkyl PAHs & 0.486 & -0.680 & NS & -0.831 \\
\hline & & 0.016 & 0.015 & & 0.041 \\
\hline & 2-methylnaphthalene & 0.4980 .013 & -0.6050 .037 & NS & -0.8500 .032 \\
\hline & 2,6-dimethylnaphthalene & 0.4810 .017 & -0.6960 .012 & -0.8570 .029 & -0.8730 .023 \\
\hline & 1,3-dimethylnaphthalene & 0.4760 .019 & -0.6860 .014 & NS & NS \\
\hline & 1,5-dimethylnaphthalene & 0.5040 .012 & -0.6860 .014 & -0.8600 .028 & -0.8480 .033 \\
\hline & 2,3,5-trimethylnaphthalene & 0.5390 .001 & -0.7040 .011 & NS & NS \\
\hline & 1-methylfluorene & 0.4050 .049 & -0.7010 .011 & NS & NS \\
\hline & 3-methylphenanthrene & NS & -0.6580 .020 & NS & NS \\
\hline & 9-methylphenanthrene & NS & -0.6850 .014 & -0.8130 .049 & NS \\
\hline
\end{tabular}

low salinity reduced the sensitivity of female fish to increased LSI upon exposure to high HEWAF. Increased liver size is a well-documented response of fish to petroleum hydrocarbon exposure, and is hypothesized to be an adaptive response to increase capacity to metabolize the hydrocarbon compounds (Heath, 1995). Increased LSI was recently observed following exposure of juvenile southern flounder (Paralichthys lethostigma) to a sediment-oil mixture (Brown-Peterson et al., 2015). The highest body burdens in SHM tended to be alkyl PAHs, particularly methylated and dimethylated naphthalene compounds, and the sum of alkyl PAHs were 2-6 times higher than the sum of parent PAHs in tissues, when they were in similar proportions in water, suggesting the possibility of metabolism of parent compounds in fish tissues (compatible with increased LSI) or preferential uptake of alkyl PAHs from water. Alkyl PAHs are generally less water soluble (more lipophilic) and have a stronger tendency to bioaccumulate in tissues (Irwin et al., 1997). The bioaccumulation of PAHs is related to the octanol-water partition coefficient $\left(\mathrm{K}_{\mathrm{ow}}\right)$, such that a compound with a high $\mathrm{K}_{\mathrm{ow}}$, indicating high hydrophobicity, would have increased potential for bioaccumulation and bioconcentration (Axelman et al., 1995). Importantly, alkylated PAHs are considered more acutely toxic than the parent PAH compound (Irwin et al., 1997; Mu et al., 2014; Turcotte et al., 2011), in terms of direct mortality and sub-lethal effects, including increased frequency of abnormal embryos (Turcotte et al., 2011).

Given that body burdens and water concentrations both varied with the environmental conditions of the exposure, the relationship between the two will best be discussed using BCF, which integrates both variables. In general, fish exposed to high HEWAF in the HYP scenario had increased bioconcentration of parent and alkyl PAHs, compared to fish exposed in the NORM scenario, indicating that hypoxia enhances the ability of the SHM to absorb hydrocarbons or decreases their ability to metabolize PAHs. The relationship of BCFs among environmental scenarios was more variable in response to low HEWAF exposure, suggesting that accumulation of PAHs is less predictable when concentrations of PAHs in the water are low. It has previously been established that there is overlap between oil and hypoxia intracellular response pathways through a common dimerization partner, ARNT/HIF-1 $\beta$,
(Mandl and Depping, 2014), which suggests the potential for synergistic toxic effects (Whitehead, 2013). Competition for this protein during periods of simultaneous exposure to oil and hypoxia could result in an impaired hypoxia response and/or reduced PAH metabolism, which may explain the higher levels of bioconcentration of PAHs in fish in the HYP scenario. Increased BCFs of alkyl PAHs and increased alkyl:parent $\mathrm{PAH}$ ratios of fish exposed to low HEWAF in the HYP scenario suggest that metabolism of alkyl PAHs may be particularly sensitive to competition for ARNT/HIF-1 $\beta$ under hypoxic conditions.

Exposure to HEWAF in hypoxic and low salinity conditions (HYP-LS scenario) tended to reduce bioconcentration of most alkyl PAHs, particularly upon exposure to low HEWAF. The relative bioconcentration of parent PAHs in the HYP-LS scenario, in relation to fish exposed in other scenarios, was less clear. Salinity has been demonstrated to influence the solubility of hydrocarbons, such that as salinity decreases, bioavailability and uptake of PAHs increases (Ramachandran et al., 2006). This suggests that BCFs of alkyl PAHs in fish from the HYP-LS scenario may have been reduced as a result of more efficient metabolism and/or excretion, rather than a reduction in uptake of alkyl PAHs from the water. Importantly, as SHM exposed to HEWAF in the HYP-LS scenario were slightly hyperosmotic to the water, the primary route of uptake of PAHs was likely through the gills. In contrast, SHM in the NORM and HYP scenarios were hypoosmotic to the brackish water, and therefore were exposed (at least in part) to PAHs through ingestion. These different routes of uptake may also contribute to the different levels of bioconcentration of PAHs observed in the present study.

In the present study, we demonstrated that HEWAF exposure in suboptimal environmental conditions resulted in exacerbation of HEWAF effects on reproduction of SHM, including both egg production and fertilization. It is possible that due to overlap of hypoxia and hydrocarbon response pathways, SHM cellular responses to hypoxia reduced the ability of the fish to tolerate HEWAF exposure, resulting in more severe effects. Synergistic toxicity of oil and hypoxia was previously demonstrated in zebrafish (Danio rerio) larvae exposed to PAH mixtures, resulting in more severe pericardial edema and mortality (Fleming and Di Giulio, 2011). Furthermore, a previous study of SHM demonstrated that hypoxia increased the severity of reproductive 
effects (decreased egg production) caused by HEWAF exposure (Hedgpeth and Griffitt, 2016).

The HYP-LS scenario exacerbated the reproductive effects of high HEWAF exposure to a larger magnitude than the HYP scenario, suggesting that SHM were more sensitive to HEWAF at a lower salinity (10 ppt vs 15 ppt). Increased toxicity of PAHs at lower salinities has been well-documented in fish (Levitan and Taylor, 1979; Ramachandran et al., 2006; Shukla et al., 2007), though none of the studies investigated reproductive toxicity. Moreover, salinity has been shown to increase toxicity of HEWAF in Gulf killifish (Fundulus grandis) larvae, an estuarine fish species commonly found in the GOM, as HEWAF caused increased mortality at lower salinities (Rodgers et al., 2018). It has also been previously reported that low salinity reduces reproduction (fewer offspring) in SHM (Dunson et al., 1998), and freshwater decreases embryo survival of Gulf killifish (Ramee and Allen, 2016), though these studies did not test salinity in combination with contaminant exposure. Of note, the difference in salinity between the brackish (NORM and HYP) and low salinity (HYP-LS) scenarios in the present study was modest ( $5 \mathrm{ppt}$ ), to determine the impact of a relatively slight fluctuation in salinity. It is possible that a lower salinity, at or near freshwater, would result in even greater exacerbation of effects than was demonstrated in the present study. Furthermore, it has been demonstrated that fish reproduction is more sensitive to endocrine disrupting chemicals in freshwater compared to saline conditions (Bosker et al., 2017), suggesting that it is possible for PAHs to act in a similar manner.

In sum, the environmental scenario played an important role in the severity of the effects of HEWAF exposure. Results from the present study suggest that SHM in areas of the GOM that experienced adverse environmental conditions during the DWH incident may have been at increased risk for reproductive effects from oil exposure. These reproductive effects could have population level impacts that could have lasting effects on GOM estuaries. These data also suggest that oil spill risk assessments that fail to consider other naturally occurring environmental stressors (i.e. hypoxia and salinity) may be underestimating risk. Moreover, data from the present study provide valuable information to inform remediation efforts following a future oil spill.

\section{Acknowledgements}

The authors acknowledge the many undergraduate and graduate students who assisted with this project, including Megan Christianson, Kirstin McLeod, Emily Gagnon, Erika Gebhard-Cote, and Brittany Jasperse. Special thanks to Dr. Christian Brückner for use of his fluorescence spectrophotometer. The authors also thank the University of Connecticut Office of Animal Care for maintenance of the Aquatic Animal Facility. This research was made possible by a grant from The Gulf of Mexico Research Initiative (SA-13-01/GoMRI-009). Data are publicly available through the Gulf of Mexico Research Initiative Information \& Data Cooperative (GRIIDC) at https://data. gulfresearchinitiative.org/data/R2.x213.000:0003 ～(DOI:10.7266/ N74M92WR).

\section{Appendix A. Supplementary data}

Supplementary material related to this article can be found, in the online version, at doi:https://doi.org/10.1016/j.aquatox.2019.05.002.

\section{References}

Adeyemi, J.A., Klerks, P.L., 2012. Salinity acclimation modulates copper toxicity in the sheepshead minnow, Cyprinodon variegatus. Environ. Toxicol. Chem. 31, 1573-1578. American Veterinary Medical Association, 2013. AVMA Guidelines for the Euthanasia of Animals. https://www.avma.org/KB/Policies/Documents/euthanasia.pdf).

Arnot, J., Gobas, F., 2006. A review of bioconcentration factor (BCF) and bioaccumula tion factor (BAF) assessments for organic chemicals in aquatic organisms. Environ. Rev. 14, 257-297.

Axelman, J., Broman, D., Näf, C., Pettersen, H., 1995. Compound dependence of the relationship log Kow and log BCF L. Environ. Sci. Pollut. Res. - Int. 2, 33-36.

Beyer, J., Trannum, H.C., Bakke, T., Hodson, P.V., Collier, T.K., 2016. Environmental effects of the Deepwater Horizon oil spill: a review. Mar. Pollut. Bull. 110, 28-51.

Bianchi, T.S., Cook, R.L., Perdue, E.M., Kolic, P.E., Green, N., Zhang, Y., Smith, R.W., Kolker, A.S., Ameen, A., King, G., et al., 2011. Impacts of diverted freshwater on dissolved organic matter and microbial communities in Barataria Bay, Louisiana, U.S.A. Mar. Environ. Res. 72, 248-257.

Bigelow, H.B., Schroeder, W.C., 1953. Fishes of the Gulf of Maine. Fishery Bull. Fish Wildlife Serv. 53.

Bosker, T., Munkittrick, K.R., MacLatchy, D.L., 2009. Challenges in current adult fish laboratory reproductive tests: suggestions for refinement using a mummichog (Fundulus heteroclitus) case study. Environ. Toxicol. Chem. 28, 2386-2396.

Bosker, T., Santoro, G., Melvin, S.D., 2017. Salinity and sensitivity to endocrine disrupting chemicals: a comparison of reproductive endpoints in small-bodied fish exposed under different salinities. Chemosphere 183, 186-196.

BP Gulf Science Data, 2015. Chemistry Data Associated With Tissue and Samples of Various Media Collected in the Gulf of Mexico from April 2010 Through March 2012. Gulf of Mexico Research Initiative Information and Data Cooperative ed.

BP Gulf Science Data, 2016. Chemistry Data Associated With Water Column Samples Collected in the Gulf of Mexico from May 2010 Through July 2012.

Brown-Peterson, N.J., Manning, C.S., Brouwer, M., Griffitt, R.J., 2013. Effects of pyrene exposure on sheepshead minnow (Cyprinodon variegatus) reproduction. J. Toxicol. Environ. Health Part A 76, 842-852.

Brown-Peterson, N.J., Krasnec, M., Takeshita, R., Ryan, C.N., Griffitt, K.J., Lay, C., Mayer, G.D., Bayha, K.M., Hawkins, W.E., Lipton, I., et al., 2015. A multiple endpoint analysis of the effects of chronic exposure to sediment contaminated with Deepwater Horizon oil on juvenile Southern flounder and their associated microbiomes. Aquat. Toxicol. 165, 197-209.

Cripe, G.M., Hemmer, B.L., Goodman, L.R., Vennari, J.C., 2009. Development of a methodology for successful multigeneration life-cycle testing of the estuarine sheepshead minnow, Cyprinodon variegatus. Arch. Environ. Contam. Toxicol. 56, 500-508.

Diaz, R.J., Rosenberg, R., 2008. Spreading dead zones and consequences for marine ecosystems. Science 321, 926-929.

Dunson, W.A., Paradise, C.J., Dunson, D.B., 1998. Inhibitory effect of low salinity on growth and reproduction of the estuarine sheepshead minnow, Cyprinodon variegatus. Copeia 1998, 235-239.

Evans, D.H., 1997. The Physiology of Fishes, second ed. CRC Press.

Fleming, C.R., Di Giulio, R.T., 2011. The role of CYP1A inhibition in the embryotoxic interactions between hypoxia and polycyclic aromatic hydrocarbons (PAHs) and $\mathrm{PAH}$ mixtures in zebrafish (Danio rerio). Ecotoxicology 20, 1300-1314.

Griffitt, R.J., 2017. Impacts of Oil Exposure During Early Life Developmental Stages in Sheepshead Minnows (Cyprinodon Variegatus) Under Different Environmental Factors. (Gulf of Mexico research Initiative Information and Data Cooperative (GRIIDC). Harte Research Institute, Texas A\&M University-Corpus, Christi.

Heath, A.G., 1995. Water Pollution and Fish Physiology, 2 edn. CRC Press.

Hedgpeth, B.M., Griffitt, R.J., 2016. Simultaneous exposure to chronic hypoxia and dissolved polycyclic aromatic hydrocarbons results in reduced egg production and larval survival in the sheepshead minnow (Cyprinodon variegatus). Environ. Toxicol. Chem. 35, 645-651.

Incardona, J.P., Swarts, T.L., Edmunds, R.C., Linbo, T.L., Aquilina-Beck, A., Sloan, C.A., Gardner, L.D., Block, B.A., Scholz, N.L., 2013. Exxon Valdez to Deepwater Horizon: comparable toxicity of both crude oils to fish early life stages. Aquat. Toxicol. 142$143,303-316$.

Irwin, R.J., VanMouwerik, M., Stevens, L., Seese, M., Basham, W., 1997. Environmental Contaminants Encyclopedia Entry on Alkyl PAHs (alkyl Homologs of PAHs). pp. 18.

Jasperse, L., Levin, M., Rogers, K., Perkins, C., Bosker, T., Griffitt, R.J., Sepúlveda, M.S. De Guise, S., 2019. Transgenerational effects of polycyclic aromatic hydrocarbon exposure on sheepshead minnows (Cyprinodon variegatus). Environ. Toxicol. Chem. 38, 638-649.

Johnson, Y.S., 2012. Determination of polycyclic aromatic hydrocarbons in edible seafood by QuEChERS-based extraction and gas chromatography-tandem mass spectrometry. J. Food Sci. 77, T131-137.

Jonsson, G., Bechmann, R.K., Bamber, S.D., Baussant, T., 2004. Bioconcentration, biotransformation, and elimination of polycyclic aromatic hydrocarbons in sheepshead minnows (Cyprinodon variegatus) exposed to contaminated seawater. Environ. Toxicol. Chem. 23, 1538-1548.

Khan, R.A., 2012. Effects of polycyclic aromatic hydrocarbons on sexual maturity of Atlantic cod, Gadus morhua, following chronic exposure. Environ. Pollut. 2, 1

Kim, M., Yim, U.H., Hong, S.H., Jung, J.H., Choi, H.W., An, J., Won, J., Shim, W.J., 2010. Hebei Spirit oil spill monitored on site by fluorometric detection of residual oil in coastal waters off Taean, Korea. Mar. Pollut. Bull. 60, 383-389.

Levitan, W.M., Taylor, M.H., 1979. Physiology of salinity-dependent naphthalene toxicity in Fundulus heteroclitus. J. Fish Res. Board Can. 35, 615-620.

Mandl, M., Depping, R., 2014. Hypoxia-inducible aryl hydrocarbon receptor nuclear translocator (ARNT) (HIF-1ß): is it a rare exception? Mol. Med. 20, 215-220.

Manning, C., Schesny, A., Hawkins, W., Barnes, D., Barnes, C., Walker, W., 1999. Exposure methodologies and systems for long-term chemical carcinogenicity studies with small fish species. Toxicol. Mech. Methods 9, 201-207.

Martínez, M.L., Feagin, R.A., Yeager, K.M., Day, J., Costanza, R., Harris, J.A., Hobbs, R.J., López-Portillo, J., Walker, I.J., Higgs, E., et al., 2012. Artificial modifications of the coast in response to the Deepwater Horizon oil spill: quick solutions or long-term liabilities? Front. Ecol. Environ. 10, 44-49.

McNutt, M.K., Camilli, R., Crone, T.J., Guthrie, G.D., Hsieh, P.A., Ryerson, T.B., Savas, O., Shaffer, F., 2012. Review of flow rate estimates of the Deepwater Horizon oil spill. Proc. Natl. Acad. Sci. 109, 20260-20267. 
Mu, J., Wang, J., Jin, F., Wang, X., Hong, H., 2014. Comparative embryotoxicity of phenanthrene and alkyl-phenanthrene to marine medaka (Oryzias melastigma). Mar. Pollut. Bull. 85, 505-515.

Nixon, Z., Zengel, S., Baker, M., Steinhoff, M., Fricano, G., Rouhani, S., Michel, J., 2016. Shoreline oiling from the Deepwater Horizon oil spill. Mar. Pollut. Bull. 107, 170-178.

Nordlie, F.G., 2006. Physicochemical environments and tolerances of cyprinodontoid fishes found in estuaries and salt marshes of eastern North America. Rev. Fish Biol. Fish. 16, 51-106.

Page, L.M., Burr, B.M., 1991. A Field Guide to Freshwater Fishes of North America, North of Mexico. Houghton Mifflin Company, Boston.

Paruk, J.D., Long, D.I., Perkins, C., East, A., Sigel, B.J., Evers, D.C., 2013. Polycyclic aromatic hydrocarbons detected in common loons (Gavia immer) wintering off coastal Louisiana. Waterbirds 37, 85-93.

Pilcher, W., Miles, S., Tang, S., Mayer, G., Whitehead, A., 2014. Genomic and genotoxic responses to controlled weathered-oil exposures confirm and extend field studies on impacts of the Deepwater Horizon oil spill on native killifish. PLoS One 9, e106351.

Pollino, C.A., Georgiades, E., Holdway, D.A., 2009. Physiological changes in reproductively active rainbowfish (Melanotaenia fluviatilis) following exposure to naphthalene. Ecotoxicol. Environ. Saf. 72, 1265-1270.

Powers, S.P., Grabowski, J.H., Roman, H., Geggel, A., Rouhani, S., Oehrig, J., Baker, M., 2017. Consequences of large-scale salinity alteration during the Deepwater Horizon oil spill on subtidal oyster populations. Mar. Ecol. Prog. Ser. 576, 175-187.

Raimondo, S., Hemmer, B.L., Lilavois, C.R., Krzykwa, J., Almario, A., Awkerman, J.A., Barron, M.G., 2016. Effects of Louisiana crude oil on the sheepshead minnow (Cyprinodon variegatus) during a life-cycle exposure to laboratory oiled sediment. Environ. Toxicol. 31, 1627-1639.

Ramachandran, S.D., Sweezey, M.J., Hodson, P.V., Boudreau, M., Courtenay, S.C., Lee, K., King, T., Dixon, J.A., 2006. Influence of salinity and fish species on PAH uptake from dispersed crude oil. Mar. Pollut. Bull. 52, 1182-1189.

Ramee, S.W., Allen, P.J., 2016. Freshwater influences on embryos, hatching and larval survival of euryhaline Gulf killifish Fundulus grandis and potential constraints on habitat distribution. J. Fish Biol. 89, 1466-1472.

Reddy, C.M., Arey, J.S., Seewald, J.S., Sylva, S.P., Lemkau, K.L., Nelson, R.K., Carmichael, C.A., McIntyre, C.P., Fenwick, J., Ventura, G.T., et al., 2012. Composition and fate of gas and oil released to the water column during the Deepwater Horizon oil spill. Proc. Natl. Acad. Sci. U. S. A. 109, 20229-20234.

Rodgers, M.L., Jones, E.R., Klinkhamer, C., Mahapatra, C.T., Serafin, J., Bosker, T., Perkins, C., Griffitt, R.J., De Guise, S., Sepúlveda, M.S., 2018. Combined effects of Deepwater Horizon crude oil and environmental stressors on Fundulus grandis embryos. Environ. Toxicol. Chem. 37, 1916-1925.

Sandoval, K., Ding, Y., Gardinali, P., 2017. Characterization and environmental relevance of oil water preparations of fresh and weathered MC-252 Macondo oils used in toxicology testing. Sci. Total Environ. 576, 118-128.

Seegar, W.S., Yates, M.A., Doney, G.E., Jenny, J.P., Seegar, T.C., Perkins, C., Giovanni, M., 2015. Migrating Tundra Peregrine Falcons accumulate polycyclic aromatic hydrocarbons along Gulf of Mexico following Deepwater Horizon oil spill. Ecotoxicology 24, 1102-1111.

Shukla, P., Gopalani, M., Ramteke, D.S., Wate, S.R., 2007. Influence of salinity on PAH Uptake from water soluble fraction of crude oil in Tilapia mossambica. Bull. Environ. Contam. Toxicol. 79, 601-605.

Simning, D., 2017. Impacts of Oil Exposure During Early Life Development Stages in Sheepshead Minnows (Cyprinodon Variegatus) Under Different Environmental Factors. University of Southern Mississippi. https://aquila.usm.edu/masters_theses/ 325.

Sundt, R.C., Bjorkblom, C., 2011. Effects of produced water on reproductive parameters in prespawning Atlantic cod (Gadus morhua). J. Toxicol. Environ. Health A 74, 543-554.

Thomas, P., Rahman, M.S., Khan, I.A., Kummer, J.A., 2007. Widespread endocrine disruption and reproductive impairment in an estuarine fish population exposed to seasonal hypoxia. Proc. R. Soc. B: Biol. Sci. 274, 2693-2701.

Turcotte, D., Akhtar, P., Bowerman, M., Kiparissis, Y., Brown, R.S., Hodson, P.V., 2011. Measuring the toxicity of alkyl-phenanthrenes to early life stages of medaka (Oryzias latipes) using partition-controlled delivery. Environ. Toxicol. Chem. 30, 487-495.

Turner, R.E., Rabalais, N.N., Justic, D., 2012. Predicting summer hypoxia in the northern Gulf of Mexico: redux. Mar. Pollut. Bull. 64, 319-324.

USEPA, 1999. Ecological Condition of Estuaries in the Gulf of Mexico. EPA 620-R098-004 U.S. Environmental Protection Agency, Office of Research and Development, National Health and Environmental Effects Research Laboratory, Gulf Ecology Division. USEPA, Gulf Breeze, Florida.

USEPA, 2002. Short-term Methods for Estimating the Chronic Toxicity of Effluents and Receiving Waters to Marine and Estuarine Organisms. Environmental Protection Agency).

USEPA, 2006. Voluntary Estuary Monitoring Manual Chapter 9: Dissolved Oxygen and Biochemical Oxygen Demand.

Vignet, C., Larcher, T., Davail, B., Joassard, L., Le Menach, K., Guionnet, T., Lyphout, L. Ledevin, M., Goubeau, M., Budzinski, H., et al., 2016. Fish reproduction is disrupted upon lifelong exposure to environmental PAHs fractions revealing different modes of action. Toxics 4 .

Whitehead, A., 2013. Interactions between oil-spill pollutants and natural stressors can compound ecotoxicological effects. Integr. Comp. Biol. 53, 635-647.

Yeudakimau, A.V., Provatas, A.A., Perkins, C.R., Stuart, J.D., 2013. Solid phase extraction and QuEChERS sample preparation methods for rapid screening of polycyclic aromatic hydrocarbons in avian blood and egg tissue by UPLC-UV. Anal. Lett. 46, 999-1011. 